Research Article

\title{
A Study on Adverse Drug Reactions in a Tertiary Care Hospital of South India.
}

\author{
Sherin Shaji*, Mahadevamma Lingaiah, Swathi Ramesh, Amal Balakrishna Kurup Kovattu \\ Department of Pharmacy Practice, East West College of Pharmacy, Bangalore, India. \\ *Corresponding author's E-mail: ppdept.ewcp@gmail.com
}

Received: 20-08-2021; Revised: 22-10-2021; Accepted: 28-10-2021; Published on: 15-11-2021.

\begin{abstract}
Medication-related adverse events or adverse drug reactions (ADRs) are harmful events caused by medication. ADRs could have profound effects on the patients' quality of life, as well as creating an increased burden on the healthcare system. ADRs are one of the rising causes of morbidity and mortality internationally, and will continue to be a significant public health issue with the increased complexity in medication, to treat various diseases in an aging society. This was a prospective and observational study conducted in medicine department of sagar hospital, Bengaluru. Patients were enrolled based on the criteria with a suitable statistical tool. Among 64 patients, 33 (51.6\%) female and $33(48.44 \%)$ were males found. ADRs were more in the age group of $41-60,32$ (50\%), less in the age group is $0-20,04$ (6.25\%). Significantly higher numbers of ADRs caused by the antibiotics 25 (39\%) followed by antihyperlipidicmic and anti-arrythmic $01(1.56 \%)$, Most of the ADRs were moderate 40 (62.5\%) and sever 01 (1.56\%) in nature. Most commonly affected organ is dermatological system $32(50 \%)$. Majority of the ADRs were associated with antibiotics. Commonly skin related ADRs was found in this study. The results provided an insight to the Health care Providers on the importance of monitoring and reporting of ADRs. Our study results emphasize a need for establishing a pharmacovigilance centre to ensure the safe use of drugs.
\end{abstract}

Keywords: Adverse drug reactions, Prospective study, India.

QUICK RESPONSE CODE $\rightarrow$

DOI:

10.47583/ijpsrr.2021.v71i01.017

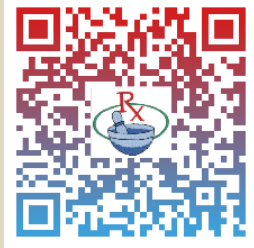

DOI link: http://dx.doi.org/10.47583/ijpsrr.2021.v71i01.017

\section{INTRODUCTION}

$\mathrm{M}$ edication-related adverse events, or adverse drug reactions (ADRs) are harmful events caused by medication. ADRs could have profound effects on the patients' quality of life, as well as creating an increased burden on the healthcare system. ADRs are one of the rising causes of morbidity and mortality internationally and will continue to be a significant public health issue with the increased complexity in medication, to treat various diseases in an aging society ${ }^{1}$. Adverse drug reactions (ADRs) are any unwanted/uncomfortable effects from medication resulting in physical, mental, and functional injuries ${ }^{2}$. Increased morbidity and mortality, prolonged hospitalization, and increased medical expense are associated with inpatients encountering $\mathrm{ADRs}^{3}$. According to several reports, ADR associated hospital admission is around $5 \%$ and almost $15-20 \%$ of patients admitted to hospitals experience ADRs ${ }^{4}$. An overall incidence of serious and fatal ADR among hospitalized patients is 6.7\% and $0.32 \%$, respectively ${ }^{5}$. Sometimes, ADR-related costs, such as hospitalization, surgery and lost productivity, exceed the cost of the medications $s^{6}$. New epidemiological studies have calculated that adverse drug reactions are the fourth to sixth leading causes of death ${ }^{7}$. As per WHO, pharmacovigilance is an activity concerned with the detection, assessment, understanding, management and prevention of adverse reactions to medicines, contributes to their safe and rational use ${ }^{8}$.

The causes and nature of adverse drug events are often complex and multi-factorial. The types of adverse reactions are classified into the following categories: dose/drug related, allergic or idiosyncratic reactions. Doserelated and drug related adverse drug reactions are usually related to the dose of the medication and are usually predictable but sometimes unavoidable ${ }^{9-12}$. It is highly dependent on the patient's sensitivity to the drug and combinations of medication used. It generally does not lead to severe ADR but is relatively common. An allergic drug reaction is when the patients develop an inappropriate reaction to the medication, which mostly could be avoided with a skin test prior to or through effective consultation and communication between primary care facilities and patients ${ }^{12}$.

\section{METHODOLOGY}

\section{Study site}

The study was conducted in Medicine Department of Sagar Hospitals, Bengaluru.

\section{Study design}

A Prospective and Observational study. 


\section{Sample size}

A total of 64 patients from Medicine Department of Sagar Hospitals, who satisfied the study criteria and consented to participate in this study were included for the study.

\section{Study period}

The study was conducted over a period of 03 months starting from December 2020 to March 2021.

\section{Study criteria}

Inclusion Criteria:

1. Patients who visited the medicine department

2. Patients with minimum 24 hours of length of hospital stay

Exclusion criteria:

1. Pregnant And Lactating Women

2. Excluded other department patients

\section{Source of data}

$\checkmark \quad$ Patient case notes

$\checkmark \quad$ Treatment chart/ Medication chart

$\checkmark \quad$ Laboratory reports

$\checkmark$ Prescriptions

$\checkmark \quad$ Personal interactions with patients

\section{Study procedure}

\section{Patient Enrolment}

Patients who were admitted in Medicine Department of Sagar Hospitals in Bengaluru during the study period, were selected and screened based on the inclusion and exclusion criteria. Patients who met the criteria and who consented for the study were enrolled.

\section{Methods of data collection}

Patients admitted to the Medicine Department of Sagar Hospitals in Bengaluru- during the study period- were screened for any Adverse Drug Reactions. Those who met the inclusion and exclusion criteria were enrolled for the study. Follow-ups were carried from the day of admission to the day of discharge of the enrolled patients. After the diagnosis was confirmed by the physician, relevant \& necessary baseline information such as the demographic details of the patient was obtained from case notes \& details of the ADR was documented with help of therapeutic data such as the name of the drug, dose, route of administration, duration etc.

\section{Assessment of Adverse Drug Reactions}

The patient's enrolled under inclusion criteria were screened by direct interaction and the complaints were assessed during the hospital admission. ADRs were recorded and documented in a suitable designed Adverse Drug Reaction forms.

\section{RESULTS AND DISCUSSION}

Table 1: Gender distribution of study population.

\begin{tabular}{|c|c|c|}
\hline Gender & Number of ADRs & Percentage (\%) \\
\hline Female & 33 & 51.56 \\
\hline Male & 31 & 48.44 \\
\hline
\end{tabular}

\section{Gender distribution of study population.}

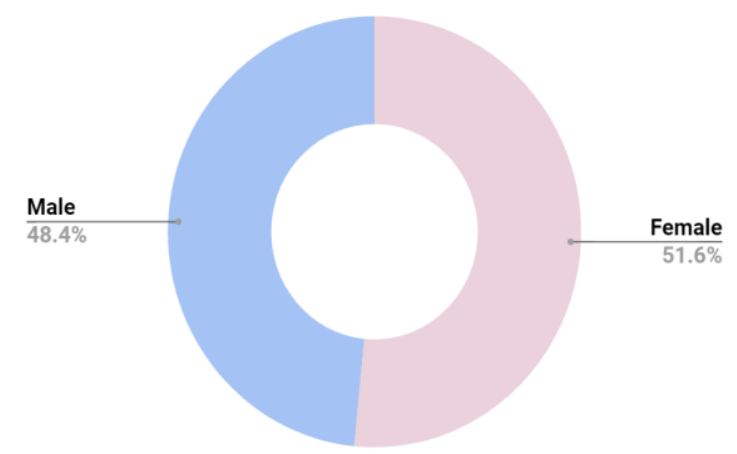

Figure 1: Gender distribution of study population.

As shown in Table no 01 and Figure no 01, out of 64 patients, 33(51.56\%) were females and 31(48.44\%) was males. Higher rate of Adverse Drug Reactions in females may be due to the variation of immunological factors, hormonal factors and polypharmacy. The study carried out by Peter JV et al. showed that majority of patients reported ADRs were females ${ }^{13}$.

Table 2: Age distribution of patients with ADRs.

\begin{tabular}{|c|c|c|}
\hline Age & Number of ADRs & Percentage (\%) \\
\hline $0-20$ & 04 & 6.25 \\
\hline $21-40$ & 10 & 15.62 \\
\hline $41-60$ & 32 & 50 \\
\hline $61-80$ & 18 & 28.12 \\
\hline
\end{tabular}

Age distribution of patients with ADRs.

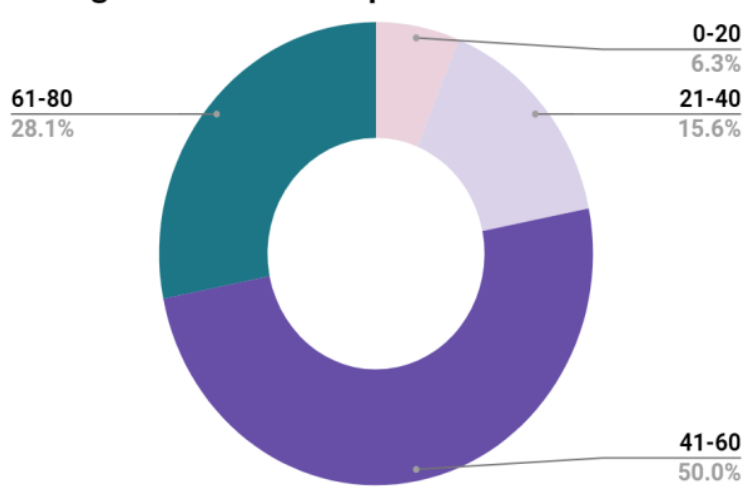

Figure 2: Age distribution of patients with ADRs.

As shown in Table no 02 and Figure no 02, middle age categories age from 41 to 60 are more prone to ADRs because of their changes in pharmacokinetics and 
pharmacodynamics, increase in burden of co-morbidities, polypharmacy, inappropriate prescribing and more number of patients admitted in this age group. The study carried out by Kumar A.et al. showed that majority of reported ADRs was middles age patients ${ }^{13}$.

Table 3: The drug class causing ADRs with their corresponding percentage.

\begin{tabular}{|c|c|c|}
\hline Class of Drugs & Number of ADRs & Percentage (\%) \\
\hline Antibiotics & 25 & 39 \\
\hline Antihyperlipidemic drugs & 01 & 1.56 \\
\hline Antidepressants & 02 & 3.12 \\
\hline Anti ulcer drugs & 04 & 6.25 \\
\hline Anti hypertensive drugs & 04 & 6.25 \\
\hline Antiviral drugs & 02 & 3.12 \\
\hline Anti diabetic drugs & 03 & 4.68 \\
\hline Anti arrhythmic drugs & 01 & 1.56 \\
\hline Anti epileptic drugs & 04 & 6.25 \\
\hline Antithrombotic drugs & 07 & 10.93 \\
\hline Anti asthmatic drugs & 01 & 1.56 \\
\hline Autacoids & 01 & 1.56 \\
\hline Laxatives & 01 & 1.56 \\
\hline Analgesics & 07 & 10.93 \\
\hline Others & 01 & 1.56 \\
\hline
\end{tabular}

As shown in Table no 03 and Figure no 03, the majority of ADRs were associated with Antibiotics 25(39\%) followed by antithrombotic 7(10.93) and analgesics 7(10.93). Cephalosporin antibiotics were the drug having majority of the ADRs. The commonly reported ADRs in this study were rash, itching and edema. The study carried out by Raut $A$. et al. showed that majority of reported ADRs was caused by antibiotics ${ }^{14}$.

Of the reported ADRs on Table no 4and Figure no 04, moderate reactions accounted for 40(62.5) followed by mild reactions $23(35.93)$. Only $1(1.56)$ of the reactions were severe. The study carried out by Stavreva et al. and Priyadarshini et al. also showed that the severity was moderate for the reported Adverse Drug Reactions while severe reactions were more followed by moderate in a study by Oshikoya et al ${ }^{15,16}$.

Table 4: Severity assessment of ADRs.

\begin{tabular}{|c|c|c|}
\hline Severity & Number of ADRs & Percentage (\%) \\
\hline Severe & 01 & 1.56 \\
\hline Moderate & 40 & 62.5 \\
\hline Mild & 23 & 35.93 \\
\hline
\end{tabular}

The drug class causing ADRs with their corresponding percentage.

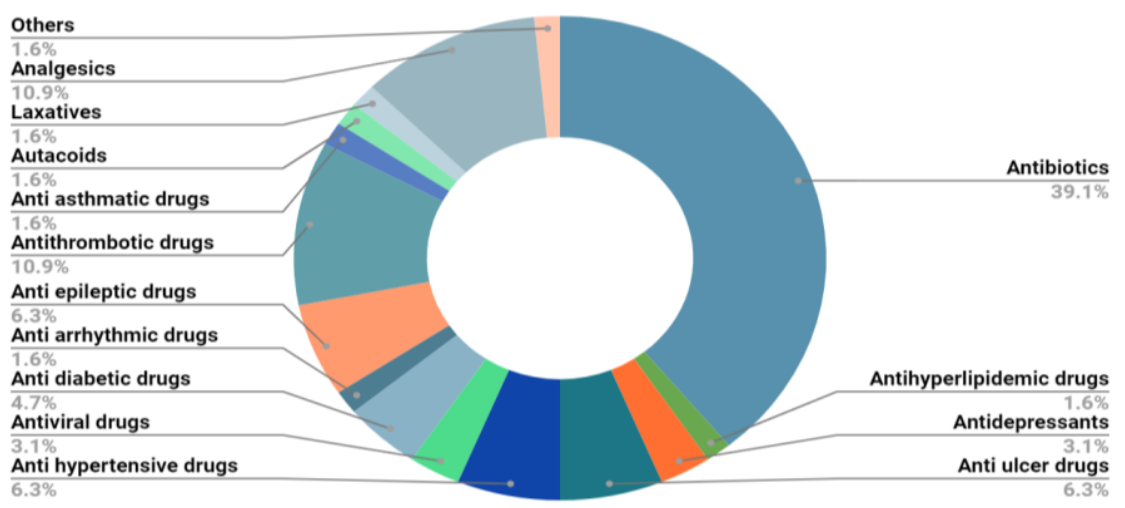

Figure 3: The drug class causing ADRs with their corresponding percentage.

Severity assessment of ADRs.

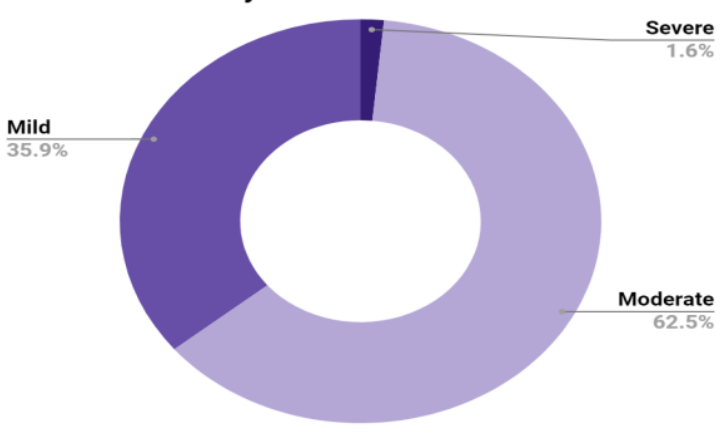

Figure 4: Severity assessment of ADRs.
Table 5: Distribution of ADRs in various organ systems.

\begin{tabular}{|r|c|c|}
\hline Organ Systems Involved & Number of ADRs & Percentage (\%) \\
\hline Dermatology & 32 & 50 \\
\hline Gastrointestinal system & 13 & 20.31 \\
\hline Endocrine system & 05 & 7.81 \\
\hline Central Nervous System & 05 & 7.81 \\
\hline Cardiovascular system & 04 & 6.25 \\
\hline Musculoskeletal system & 04 & 6.25 \\
\hline Renal system & 01 & 1.56 \\
\hline
\end{tabular}




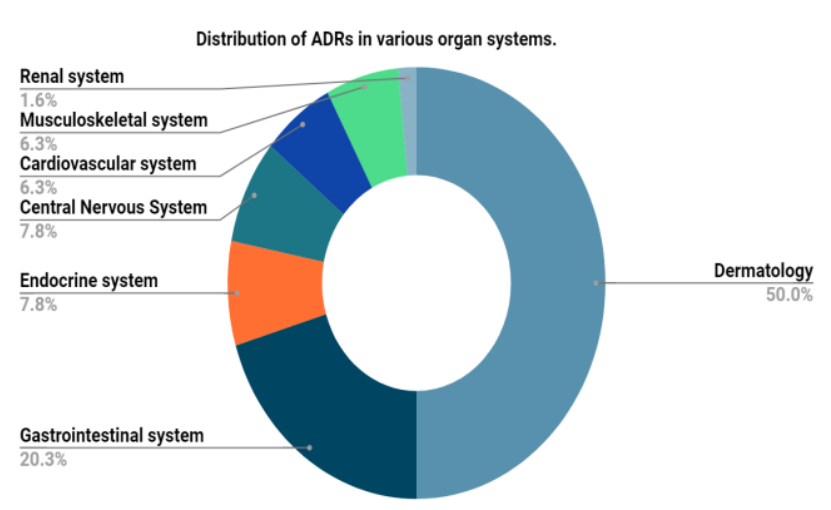

Figure 5: Distribution of ADRs in various organ systems.

As shown in Table no 5and Figure no 05, the most commonly affected organ is the dermatological system $32(50 \%)$ followed by the gastrointestinal tract $13(20.31)$, central nervous system 5(7.81) and endocrine system 5(7.81). Skin affected more ADRs due to the properties of a drug that increase the risk of a drug-induced hypersensitivity reaction.

Table 6: Classification of ADRs.

\begin{tabular}{|c|c|c|}
\hline Types & Number of ADRs & Percentage (\%) \\
\hline TYPE A (Augmented) & 45 & 70.31 \\
\hline TYPE B (Bizzare) & 19 & 29.68 \\
\hline
\end{tabular}

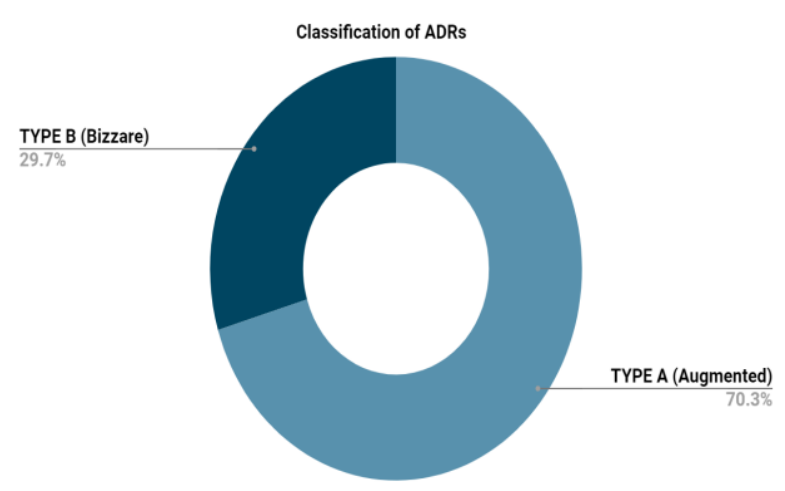

Figure 6: Distribution of ADRs in various organ systems.

As shown in Table no 6and Figure no 06, Type A 45(70.31) was the most common compared to Type B 19(29.68) reactions according to the ADR classification by Rawlin and Thomson. Type A reactions are dose related and thus were preventable from their known pharmacology and therefore all of them were potentially avoidable. The study carried out by Oshikoya K.A. et al. showed that majority of reported ADRs was reported by Type $A$ that is is Bizzare ${ }^{17}$.

\section{CONCLUSION}

Majority of the ADRs were associated with antibiotics. Commonly skin related ADRs was found in this study. The results provided an insight to the health care providers on the importance of monitoring and reporting of ADRs. Our study results emphasize a need for establishing a pharmacovigilance centre to ensure the safe use of drugs.

\section{REFERENCES}

1. Hadi MA, Neoh CF, Zin RM, Elrggal ME, Cheema E. Pharmacovigilance: pharmacists' perspective on spontaneous adverse drug reaction reporting. Integrated Pharmacy Res Pract. 2017; 6: 91-8.

2. Bates DW, Cullen DJ, Laird N, Petersen LA, Small SD, Servi D, Laffel G, Sweitzer BJ, Shea BF, Hallisey R, et al. Incidence of adverse drug events and potential adverse drug events. Implications for prevention. ADE Prevention Study Group. JAMA. 1995;274(1):29-34. PMID: 7791255.

3. Classen DC, Pestotnik SL, Evans RS, Lloyd JF, Burke JP. Adverse drug events in hospitalized patients. Excess length of stay, extra costs, and attributable mortality. JAMA. 1997 Jan 22-29; 277(4): 301-6. PMID: 9002492.

4. Einarson TR. Drug-related hospital admissions. Ann Pharmacother. 1993 Jul-Aug; 27(7-8): 832-40. doi: 10.1177/106002809302700702. PMID: 8364259.

5. Lazarou J, Pomeranz BH, Corey PN. Incidence of adverse drug reactions in hospitalized patients: a meta-analysis of prospective studies. JAMA. $1998 \mathrm{Apr}$ 15; 279(15): 1200-5. doi: 10.1001/jama.279.15.1200. PMID: 9555760.

6. World Health Organization. Fact sheet No293. Medicines: safetyof medicines - adverse drug reactions. Geneva: World HealthOrganization; 2008.5.

7. Srinivasan R, Ramya G. Adverse drug reaction causality assess-ment.Int J Res Pharm Chem2011; 1(3): 606-11.

8. World Health Organization. Pharmacovigilance. Available

from:<http://www.who.int/medicines/areas/quality_ safety/safety_effi-cacy/pharmvigi/en/index.html> accessed 10 January 2015

9. Marcum ZA, Handler SM, Boyce R, Gellad W, Hanlon JT. Medication misadventures in the elderly: a year in review. Am J Geriatr Pharmacother. 2010; 8(1): 77-83.

10. Coxon J, Rees J. Avoiding medical errors in general practice. Trends Urol Men's Health. 2015; 6(4): 13-7.

11. Avery AJ, Ghaleb M, Barber N, Dean Franklin B, Armstrong SJ, Serumaga B, et al. The prevalence and nature of prescribing and monitoring errors in English general practice: a retrospective case note review. Brit J General Pract. 2013; 63(613): e543-e53.

12. Galbraith A, Bullock S, Manias E, Hunt B, Richards A. Fundamentals of pharmacology: an applied approach for nursing and health. Routledge:London; 2015

13. Peter JV, Varghese GH, Alexander H, Tom NR, Swetha Lakshmi V, Truman C,et al. Patterns of adverse drug reaction in the medical wards of a teaching 
hospital: A prospective observational cohort study. Curr Drug Saf 2016; 11: 164-71.

14. Kumar A, Kansal D, Sharma P, Bhardwaj A, Swaraj S. To study the pattern of adverse drug reactions among patients hospitalized in the medical wards of a tertiary care hospital. Int J Basic Clin Pharmacol 2016; 5: 19727.

15. Priyadharsini R., Surendiran A., Adithan C., Sreenivasan S., Sahoo Firoj Kumar. A study on adverse drug reactions in paediatric patients. J. Pharmacol. Pharmacother. 2011; 2(4): 277-280.
16. Stavreva G., Pendicheva D., Pandurska A., Marev R. Detection of adverse drug reactions to antimicrobial drugs in hospitalized patients. Trakia J. Sci. 2008; 6(1): 7-9.

17. Oshikoya K.A., Njokanma O.F., Chukwara H.A., Ojo I.O. Adverse drug reactions in Nigerian children. Paediatr. Perinat. Drug Ther. 2007; 8: 81-88. doi:10.1185/146300907X199858.

Source of Support: The author(s) received no financial support for the research, authorship, and/or publication of this article.

Conflict of Interest: The author(s) declared no potential conflicts of interest with respect to the research, authorship, and/or publication of this article.

For any question relates to this article, please reach us at: editor@globalresearchonline.net New manuscripts for publication can be submitted at: submit@globalresearchonline.net and submit_ijpsrr@rediffmail.com 